\title{
The tolerance of proton radiotherapy — preliminary results
}

 \\ Anna Patla², Tomasz Skóra ${ }^{1}$, Dominika Wojton-Dziewońska ${ }^{1}$ Eleonora Góra ${ }^{3}$, \\ Damian Kabat ${ }^{3}$, Kamil Kisielewicz ${ }^{3}$, Tomasz Kajdrowicz ${ }^{4}$, Renata Kopeć ${ }^{4}$
}

Introduction. Because the specific proton beam dose distribution (i.e. the so-called 'Bragg curve'), proton radiotherapy ensures that the high-dose region is precisely confined to the target volume while minimizing the dose delivered to healthy tissues/critical organs surrounding the tumour or to those lying in the path of the proton beam. This method has been used for patients in Kraków since November 2016.

Aim. To report the early tolerance outcomes to proton radiotherapy in patients completing their treatment just before the end of August 2017.

Materials and methods. Study subjects were 47 patients who had completed their treatment before the end of August 2017 with a mean age of 41.6 years (range: 16-76, median: 40). The most frequent diagnoses were skull base tumours (22 pts. - 46.8\%) and brain G1 or G2 gliomas (17 pts. - 36.2\%), whereas the most frequent histological types were chordomas (17 pts. - 36.2\%). Proton radiotherapy was administered by pencil beam scanning and consisted of using the intensity modulated proton therapy (IMPT) technique. The total dose given per cancer type averaged as follows: (i) 70 and $74 \mathrm{~Gy}(\mathrm{RBE})$, for respectively chodrosarcomas and chordomas, (ii) $54 \mathrm{~Gy}$ (RBE) for brain gliomas and (iii) $70 \mathrm{~Gy}(\mathrm{RBE})$ for paranasal sinuses tumours.

Early tolerance was prospectively evaluated and measured according to the CTCAE scale, version 4.03.

Results. In all, 91 side effects (SE) were recorded in 44 patients. The intensity of SEs were as following: 62 SEs (68.1\%) were of grade 1 intensity, 21 SEs (23.1\%) were of grade 2 and 8 SEs (8.8\%) were of grade 3. The most frequently developed SEs were skin reactions (29 pts. - 61.7\%) or oral/pharyngeal mucositis (20 pts. - 42.6\%).

Because the patient follow-up period was short, presented results only describes the early tolerance to this therapy. Our findings of mild intensities for the most early side effects, at (grades 1 or 2) are consistent with other published studies.

NOWOTWORY J Oncol 2017; 67, 3: 157-161

Key words: proton radiotherapy, early tolerance, side effects, pencil beam scanning

\section{Introduction}

Using proton beams for radiotherapy was first proposed by Robert R. Wilson in his paper published in 1946 [1]. He pointed out that protons have advantages over photons because of their physical properties. Their specific energy deposition is responsible for the unique characteristic of dose distribution (i.e. the so-called 'Bragg curve') where negligible doses are deposited distal to the Bragg peak [1-4].

\footnotetext{
${ }^{1}$ Clinic of Oncology, Maria Skłodowska-Curie Memorial Cancer Centre and Institute of Oncology, Branch in Kraków, Poland ${ }^{2}$ Department of Radiotherapy, Maria Skłodowska-Curie Memorial Cancer Centre and Institute of Oncology Branch in Kraków, Poland

${ }^{3}$ Deparment of Medical Physics, Maria Skłodowska-Curie Memorial Cancer Centre and Institute of Oncology Branch in Kraków, Poland

${ }^{4}$ Bronowice Cyclotron Centre, Henryk Niewodniczański Institute of Nuclear Physics Polish Academy of Sciences Kraków, Poland
} 
In contrast to photon radiotherapy, proton radiotherapy ensures a greater precision in confining the high-dose region to the target volume while minimizing the dose delivered to healthy tissues and/or critical organs surrounding the tumour, or to those lying in the path of the proton beam [1-7]. In theory, proton radiotherapy enables dose escalation without increasing the risk of side effects (SE) or complications. The clinical benefits of proton radiotherapy are thus to either improve local control or in reducing toxicity [8-11]. The physical properties of protons enable clinical indications to be determined, especially in radio-resistant tumours localized within critical organs $[6,7]$.

There are two methods of proton beam delivery: passive scattering and active beam scanning. In the case of passive scattering (SOBP — Spread-Out Bragg Peak), with the intention of ensuring target coverage, spread Bragg peak is created with the help of a range modulator, e.g. by a modulation wheel. In the active scanning method, the narrow pencil beam is moved by means of magnetic deflection. The dose is delivered to the target volume spot by spot in successive layers at different depths (starting from the deepest at the highest energy). The energy of the proton beam changes the Bragg peak depth. The active pencil beam scanning method enables using the intensity-modulated proton therapy (IMPT) method in proton radiotherapy. There are two different possible ways of optimising the dose: single-field optimization (SFO) and multi-field optimization (MFO) $[4,8]$.

A proton radiotherapy procedure for patients with nonocular malignancies, (a proton radiotherapy procedure for patients with uveal melanomas performed since 2011), was developed thanks to a collaboration between two Polish institutions: the Kraków branch of the Maria Skłodowska-Curie Memorial Cancer Centre and Institute of Oncology, (COI-OK) responsible for the medical side and the Henryk Niewodniczański Institute of Nuclear Physics at the Polish Academy of Sciences (IFJ PAN) in Kraków (cyclotron owner and procurer of the proton beam). The first patients underwent proton radiotherapy in November 2016 [12-15]. Eligibility criteria were specified in the Ordinance of the Minister of Health published $6^{\text {th }}$ June 2016 [16].

This study aims to describe early tolerance to proton radiotherapy in a group of patients who had completed their treatment just prior to the end of August 2017.

\section{Materials and methods Patients}

Between November 2016 and August 2017, 68 patients from the $\mathrm{COI}-\mathrm{OK}$ underwent a course of proton radiotherapy. At the time the present analysis was conducted, i.e. towards the end of August 2017, 47 patients (69.1\%) had completed their treatment and who constitute the subjects of this study. Their mean age was 41.6 years (range: $16-76$, median: 40 ).
Table I presents the clinicopathological and treatment characteristics of the 47 patient subjects.

The most frequent diagnoses were skull base tumours (22 pts. - 46.8\%) and brain gliomas (17 pts. - 36.2\%), whereas the most frequent histological types of malignancy were as follows: chordomas (17 pts. - 36.2\%), brain gliomas G1 (11 pts. - 23.4\%) and chondrosarcomas (9 pts. - 19.1\%).

\section{Proton radiotherapy}

This was given as an adjuvant therapy following surgery (neurosurgery) on 40 patients (85.1\%), who had either received ensuing microscopically non-radical surgical treatment (24 patients $-51,1 \%$ ) or as a result of local recurrence (in 16 patients - 34\%). In the other 7 patients (14.9\%), proton radiotherapy was administered after a biopsy (in this case a diagnostic procedure to confirm the presence of a malignancy).

Proton radiotherapy was given by means of pencil beam scanning generated by the Proteus- 235 cyclotron located at the Bronowice Cyclotron Centre (CCB) IFJ PAN. The energy spectrum of the protons averaged from 70 to $230 \mathrm{MeV}$.

For proton radiotherapy planning purposes, an Eclipse treatment external beam planning system (Varian Medical Systems v. 7.13) was employed for all our patients. Inverse planning rules were used for SFO (2 patients - $4.3 \%$ ) or MFO (45 patients - 95.7\%) based on the intensity modulated proton therapy (IMPT) technique. The robustness of each plan regarding the $2 \mathrm{~mm}$ range uncertainties and dose uncertainties of $3.5 \%$ in the scanning proton beam range were used for 'the worst scenario' analysis method.

The radiotherapy dose was prescribed in terms of the RBE (relative biological effectiveness) weighted absorbed dose - Gy(RBE). The single RBE value equalled 1.1 for protons applied in the treatment planning system. The classical fractionation schedule was used; the fractional dose ranging between 1.8 and $2.0 \mathrm{~Gy}(\mathrm{RBE})$.

The total dose according to type of the malignancy type averaged as follows: (i) 70 and $74 \mathrm{~Gy}(\mathrm{RBE})$ for respectively chodrosarcomas and chordomas, (ii) $54 \mathrm{~Gy}(\mathrm{RBE})$ for brain gliomas and (iii) $70 \mathrm{~Gy}$ (RBE) for paranasal sinuses tumours.

\section{Tolerance to proton radiotherapy}

During the treatment period the tolerance was prospectively evaluated and measured twice weekly as well as during all follow up visits. The early side effects/complications were detailed by a physician and measured according to the CTCAE scale (Common Terminology Criteria of Adverse Events), version 4.03.

\section{Results}

During the course of the proton radiotherapy, there were 91 side effects (SE) recorded in 44 patients; the remaining 3 patients being without any side effects. The intensity of 83 SEs (91.2\%) was mild, with 62 SEs (68.1\%) being grade 1 
Table I. Clinicopathological and therapeutic characteristics of the 47 patient group undergoing proton radiotherapy

\begin{tabular}{|c|c|c|c|}
\hline Feature & & Number of patients & $\%$ \\
\hline \multirow[t]{2}{*}{ Age } & $\leq 40$ & 26 & 55.3 \\
\hline & $>40$ & 21 & 44.7 \\
\hline \multirow[t]{2}{*}{ Gender } & Female & 23 & 48.9 \\
\hline & Male & 24 & 51.1 \\
\hline \multicolumn{4}{|c|}{ Clinical diagnosis according to: } \\
\hline ICD-10 code: & Anatomical regions: & & \\
\hline \multirow[t]{2}{*}{ C41 } & Skull base & 22 & 46.8 \\
\hline & Cervical or lumbo-sacral spinal region & 5 & 10.6 \\
\hline C71 & Brain & 17 & 36.2 \\
\hline C31 & Paranasal sinuses & 3 & 6.4 \\
\hline \multicolumn{4}{|c|}{ Histological diagnosis of malignancy } \\
\hline & Chordoma & 17 & 36.2 \\
\hline & Chondrosarcoma & 9 & 19.1 \\
\hline & Glioma G1 & 11 & 23.4 \\
\hline & Glioma G2 & 6 & 12.8 \\
\hline & Adenoid cystic carcinoma & 2 & 4.3 \\
\hline & Mucoepidermoid carcinoma & 1 & 2.1 \\
\hline & Esthesioneuroblastoma & 1 & 2.1 \\
\hline \multicolumn{4}{|c|}{ Proton radiotherapy } \\
\hline & After surgery: & & \\
\hline & Microsopically non-radical & 24 & 51.1 \\
\hline & Recurrence & 16 & 34.0 \\
\hline & After biopsy (only) & 7 & 14.9 \\
\hline \multicolumn{4}{|c|}{ Optimization treatment plan method: } \\
\hline & MFO (multi-field optimization) & 45 & 95.7 \\
\hline \multirow{2}{*}{\multicolumn{2}{|c|}{ SFO (single-field optimization) }} & 2 & 4.3 \\
\hline & & $\mathrm{C} 41$ & C31 \\
\hline & Mean dose $[\mathrm{Gy}(\mathrm{RBE})]$ according to ICD-10 & 74.0 & 70.0 \\
\hline
\end{tabular}

intensity, 21 SEs (23.1\%) of grade 2 intensity and the other 8 SEs (8.8\%) of moderate intensity (grade 3 ).

Table Il presents the side effects and their intensity grade according to the irradiated anatomical regions.

Skin reactions (dermatitis) were observed in 29 patients (61.7\%). Mucous reactions (mucositis) in the pharynx or oral cavity were found in 20 patients (42.6\%), of whom all received radiotherapy in the head and neck region $(\mathrm{H} \& \mathrm{~N})$ : 16 patients had skull base tumours, 3 patients with paranasal sinuses tumours and 1 patient with a cervical spine tumour. Alopecia occurred in 11 patients (23.4\%) treated for brain gliomas (9 pts.) or skull base tumours (2 pts.). Ten patients (21.3\%) experienced pain, with 50\% suffering headaches; being mainly those treated for brain gliomas. Middle ear effusion developed in 9 patients (19.1\%). Other complications occurring during proton radiotherapy included nausea (7 pts. $-10.6 \%)$, anorexia (4 pts. $-9.5 \%$ ) and fatigue (4 pts. $-9.5 \%)$.
Grade 3 side effects developed in 5 out of the 29 patients (17.2\%) who had developed dermatitis and in 3 out of 20 cases (15\%) where mucositis occurred. It should however be pointed out that none of our patients needed to discontinue radiotherapy. Furthermore, these complications completely subsided during the time between completed proton radiotherapy and the first follow-up visit.

\section{Discussion and conclusions}

Our findings as outlined above do not significantly differ from other published studies. Nevertheless, in our case we administered proton radiotherapy based on pencil beam scanning in Kraków for 10 months. The follow-up period for our patients was too short to fully assess the tumour response to proton radiotherapy. Our study only thus describes the early tolerance outcomes of patients for this type of therapy. We have demonstrated that the intensity of most early side effects was mild with grades 1 and 2 predominating (91\% 
Table II. The type of early-stage side effects and their severity (graded by the CTCAE scale) according to irradiated anatomical regions

\begin{tabular}{|c|c|c|c|c|c|}
\hline Type of complications & Grade & $\begin{array}{l}\text { Skull base tumours } \\
\qquad \begin{array}{c}N=22 \\
(100 \%)\end{array}\end{array}$ & $\begin{array}{l}\text { Brain gliomas } \\
\qquad \begin{array}{l}N=17 \\
(100 \%)\end{array}\end{array}$ & $\begin{array}{l}\text { Paranasal sinuses tumours } \\
\qquad \begin{array}{c}\mathrm{N}=3 \\
(100 \%)\end{array}\end{array}$ & $\begin{array}{c}\text { Cor L-S* spine } \\
\text { tumours } \\
\mathrm{N}=5 \%(100 \%)\end{array}$ \\
\hline \multirow[t]{4}{*}{ Dermatitis } & G0 & $13(59.1 \%)$ & $4(23.5 \%)$ & - & $1(20 \%)$ \\
\hline & G1 & $7(31.8 \%)$ & $9(52.1 \%)$ & $1(33.3 \%)$ & $2(40 \%)$ \\
\hline & G2 & $1(4.5 \%)$ & $3(17.6 \%)$ & $1(33.3 \%)$ & - \\
\hline & G3 & $1(4.5 \%)$ & $1(5.9 \%)$ & $1(33.3 \%)$ & $2(40 \%)$ \\
\hline Mucositis & G0 & $6(27.3 \%)$ & $17(100 \%)$ & - & $4(80 \%)$ \\
\hline \multirow[t]{3}{*}{ (oral/pharynx) } & G1 & $12(54.5 \%)$ & - & $1(33.3 \%)$ & - \\
\hline & G2 & $2(9.1 \%)$ & - & $1(33.3 \%)$ & $1(20 \%)^{* *}$ \\
\hline & G3 & $2(9.1 \%)$ & - & $1(33.3 \%)$ & - \\
\hline \multirow[t]{3}{*}{ Alopecia (temporary) } & G0 & $21(95.5 \%)$ & $8(47.1 \%)$ & $2(66.7 \%)$ & $5(100 \%)$ \\
\hline & G1 & $1(4.5 \%)$ & $4(23.5 \%)$ & $1(33.3 \%)$ & - \\
\hline & G2 & - & $5(29.4 \%)$ & - & - \\
\hline \multirow[t]{3}{*}{ Pain } & G0 & 17 (77.3\%) & $14(82.4 \%)$ & $3(100 \%)$ & $4(80 \%)$ \\
\hline & G1 & $4(18.2 \%)$ & $2(11.8 \%)$ & - & - \\
\hline & G2 & $1(4.5 \%)$ & $1(5.9 \%)$ & - & $1(20 \%)$ \\
\hline \multirow[t]{3}{*}{ Middle ear effusion } & G0 & $13(59.1 \%)$ & $17(100 \%)$ & $3(100 \%)$ & $5(100 \%)$ \\
\hline & G1 & $8(36.4 \%)$ & - & - & - \\
\hline & $\mathrm{G} 2$ & $1(4.5 \%)$ & - & - & - \\
\hline \multirow[t]{3}{*}{ Nausea } & G0 & $17(77.3 \%)$ & $17(100 \%)$ & $3(100 \%)$ & $5(100 \%)$ \\
\hline & G1 & $3(6,4 \%)$ & - & - & - \\
\hline & G2 & $2(13.6 \%)$ & - & - & - \\
\hline \multirow[t]{2}{*}{ Anorexia } & G0 & $18(81.8 \%)$ & 17 (100\%) & $3(100 \%)$ & $5(100 \%)$ \\
\hline & G1 & $4(18.2 \%)$ & - & - & - \\
\hline \multirow[t]{3}{*}{ Fatigue } & G0 & $18(81.8 \%)$ & $17(100 \%)$ & $3(100 \%)$ & $5(100 \%)$ \\
\hline & G1 & $3(13.6 \%)$ & - & - & - \\
\hline & G2 & $1(4.5 \%)$ & - & - & - \\
\hline
\end{tabular}

${ }^{*}$ C or L-S: cervical or lumbo-sacral spine region; **patient with tumour located in the cervical spine

of all SEs). Indeed, these observations are in line with those reported in other studies [11,17-19].

Combs et al. [20] studied proton and other ion therapies given to patients suffering from skull base or brain tumours and found that the most frequent stage SEs included hair loss in $37 \%$ of cases, and headaches and fatigue in $27 \%$ of cases. Our study showed that similar SEs were rarely observed in the 39 patients with tumours at similar anatomical regions (i.e. the skull base or brain) and consisted of hair loss in $25.6 \%$ of cases, fatigue in $10.3 \%$ and headaches in $20.5 \%$. In addition, these patients also experienced nausea (12.3\%) and middle ear effusion (23.1\%), in keeping with other published studies $[18,19]$.

A study by Grosshaus et al. [19] on 15 patients with skull base tumours demonstrated that they all experienced side effects of either grade 1 or grade 2 intensity with the most common being low-grade fatigue (10 pts.) or nausea ( $8 \mathrm{pts}$.). Feuwert et al. [18] showed that all their patient subjects who had undergone proton radiotherapy on the skull base developed grade 1 or grade 2 early side effects.
The aforementioned studies [17-19] also showed that the side effects/complications which developed on the skin during proton radiotherapy consisted of mild erythema but this contrasted with our own study observations. Five out of 47 (10.6\%) patients had grade 3 side effects which affecting the skin (dermatitis developed in 5 patients) which coexisted with grade 3 side effects affecting the oral/pharynx mucous membrane in 3 patients (i.e. mucositis developed in 2 patients treated for tumours located at the skull base or in the paranasal sinus in 1 patient).

The early side effects of the intensities experienced by our patients is interesting. Because a proton beam has a relatively low entrance dose, the expected tolerance to this treatment should prove to be rather satisfactory. Treatment volumes are however complex targets of variable thickness and depths for which the proton energy requires modulation so as to cover the necessary area. This procedure may cause significant losses in skin-sparing effects, especially in those targets requiring modulation (i.e. targets in close proximity to the skin) [21]. 
In summary, the advantage of proton radiotherapy is to reduce the integral dose, being partly due to the absence of an exit dose beyond the Bragg peak. The other factor reducing the integral dose is pencil beam scanning where the delivery of proton radiotherapy generates secondary neutrons only inside the patient's body, as opposed to the passive scattered method where neutrons are generated both in the treatment head and inside the patient [22]. Decreasing the integral dose leads to a reduced risk of secondary cancer [23-25].

Our modest experience of using proton radiotherapy together with that of other published studies confirm the potential therapeutic benefits of this treatment method. Nevertheless, proton radiotherapy remains an experimental method, and requires hard clinical evidence from prospective clinical trials to confirm such findings.

\section{Aknowledgements}

The authors wish to thank Professor Marek Jeżabek (Head of the Henryk Niewodniczański Institute of Nuclear Physics PAN in Kraków) and Professor Jerzy Jakubowicz (Head of the Maria Skłodowska-Curie Memorial Cancer Centre and Institute of Oncology, Kraków Branch) for their collaboration in conducting the proton radiotherapy on our Polish patient subjects.

Conflict of interests: none declared

\section{Beata Sas-Korczyńska, MD, PhD}

Associate Professor

Clinic of Oncology

Maria Skłodowska-Curie Memorial Cancer Centre

and Institute of Oncology

Garncarska St. 11

31-115 Kraków, Poland

e-mail:z5korczy@cyf-kr.edu.pl

Received: 25 Sept 2017

Accepted: 2 Oct 2017

\section{References}

1. Wilson RR. Radiological use of fast protons. Radiology 1946; 47: 487-491.

2. Hall E. Protons for radiotherapy: a 1946 proposal. Lancet Oncol 2009; 10: 196.
3. Alexander C, Crumley $C$, Ho P. Proton use in radiotherapy: superior treatment or flavour of the month - an overview. J Med Imaging Rad Sci 2016; 47: 9-12.

4. Chhabra A, Langen K, Mehta MP. An overview of modern proton therapy. Chin Clin Oncol 2016; 5: 48-50.

5. Paganetti $\mathrm{H}$, van Luijk P. Biological considerations when comparing proton therapy with photon therapy. Semin Radiat Oncol 2013; 23: 77-87.

6. Uhl M, Herfarth $\mathrm{K}$, Debus J. Comparing the use of protons and carbon ions for treatment. Cancer J 2014; 20: 433-439.

7. Jiang GL. Particle therapy for cancers: a new weapon in radiation therapy. Front Med 2012; 6: 165-172.

8. Bekelman JE, Asch DA, Tochner Z et al. Principles and reality of proton therapy treatment allocation. Int J Radiat Oncol Biol Phys 2014; 89: 499-508.

9. De Ruysscher D, Mark Lodge $M$, Jones B et al. Charged particles in radiotherapy: a 5-year update of systematic review. Radiother Oncol 2012; 103: 5-7.

10. Olsen DR, Bruland OS, Frykholm G et al. Proton therapy - a systematic review of clinical effectiveness. Radiother Oncol 2007: 83: 123-132.

11. Noel G, Gondi V.Proton therapy for tumors of the base of the skull. Chin Clin Oncol 2016; 5: 51-67.

12. www.terapiaprotonowa.pl.

13. Sas-Korczyńska B, WalasekT, Romanowska-Dixon B. Radioterapia hadronowa w Krakowie - przeszłość, teraźniejszość i przyszłość. Nowotwory J Oncol 2014; 64: 251-257.

14. Romanowska-Dixon B, Pogrzebielski A, Bogdali A et al. Radioterapia protonowa czerniaka błony naczyniowej — wstępne wyniki leczenia. Klinika Oczna 2012; 114: 173-179.

15. Sas-Korczyńska B, Markiewicz A, Romanowska-Dixon B et al. Preliminary results of proton radiotherapy for choroidal melanoma - the Kraków experience. Contemp Oncol 2014; 18: 359-366.

16. Rozporządzenie Ministra Zdrowia z dnia 6 czerwca 2016 roku. Dz. U. z 2016, poz. 855.

17. Shih HA, Sherman JC, Nachtgall LB et al. Proton therapy for low-grade gliomas: results from a prospective trial. Cancer 2015; 121: 1712-1719.

18. Feuvret $L$, Bracci $S$, Calugaru V et al. Efficacy and safety of adjuvant proton therapy combined with surgery for chondrosarcoma of the skull base: a retrospective, population-based study. Int J Radiat Oncol Biol Phys 2016; 95: 312-321.

19. Grosshans DR, Zhu XR, Melancon A et al. Spot scanning proton therapy for malignancies of the base of skull: treatment planning, acute toxicities, and preliminary clinical outcomes. Int J Radiat Oncol Biol Phys 2014; 90: 540-546.

20. Combs SE, Kessel K, Habermehl D et al. Proton and carbon ion radiotherapy for primary brain tumors and tumors of the skull base. Acta Oncol 2013; 52: 1504-1509.

21. Leeman JE, Romesser PB, Zhou Y et al. Proton therapy for head and neck cancer: expanding the therapeutic window. Lancet Oncol 2017; 18: e254-e265.

22. Mali SB. Proton therapy for head and neck cancer. Oral Oncol 2015 51: e10-12.

23. Paganetti $\mathrm{HH}$, van Luijk P. Biological considerations when comparing proton therapy with photon therapy. Semin Radiat Oncol 2013; 23: 77-87.

24. Athar BS, Paganetti H. Comparison of second cancer risk due to out-of-field doses from 6-MV IMRT and proton therapy based on 6 pediatric patient treatment plans. Radiother Oncol 2011; 98: 87-92.

25. Steneker M, Lomax A, Schneider U. Intensity modulated photon and proton therapy for the treatment of head and neck tumors. Radiother Oncol 2006; 80: 263-267. 